\title{
Rectal perforation due to benign stricture caused by rectal burns associated with hot coffee enemas
}

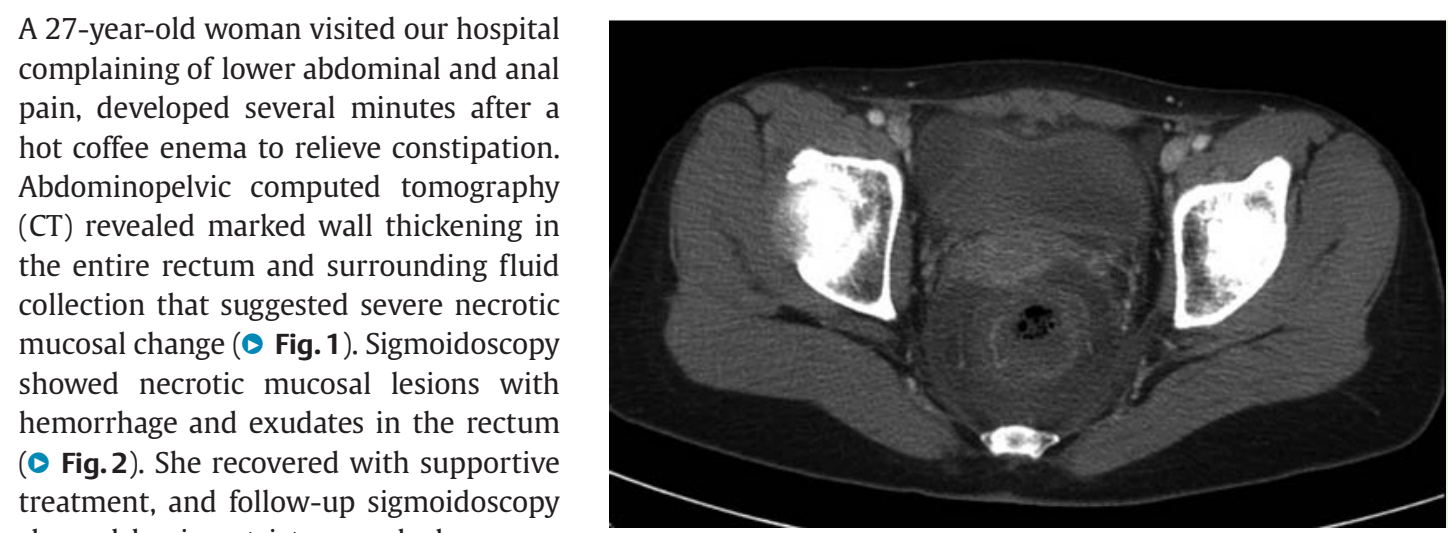
showed benign stricture and ulcer scars ( $\bullet$ Fig. 3). On the $46^{\text {th }}$ clinical day, the patient revisited the emergency department for terrible abdominal pain that had suddenly developed during straining and bowel movements. She was diagnosed with rectal perforation and peritonitis on the basis of CT scans. Laparoscopy revealed a 4-cm perforation of the upper rectum with fecal soilage ( $\bullet$ Fig.4). Primary repair and temporary colostomy was performed. On the $130^{\text {th }}$ clinical day, she was asymptomatic and sigmoidoscopy showed scarring with mild stricture ( $\bullet$ Fig. 5). Finally, she was discharged in satisfactory condition after a colostomy take-down procedure.

In alternative medicine, coffee enemas are used to treat various diseases, including cancer and constipation, without valid evidence of efficacy [1]. The potential complications of coffee enemas are not well known, but include rectal burns, proctocolitis, benign stricture, and even death [2-6]. Recently, three cases of colorectal complications caused by coffee enema were reported, two cases of rectal burns by thermal injury $[4,5]$, and a third case of proctocolitis by chemical irritation [6]. To our knowledge, this is the first case of spontaneous rectal perforation from benign stricture caused by hot coffee enemas, and the first to outline the natural history of rectal burns associated with hot coffee enemas. This case suggests that coffee enemas may lead to serious complications and their use as an alternative medical treatment should be reconsidered.

Endoscopy_UCTN_Code_CPL_1AJ_2AH

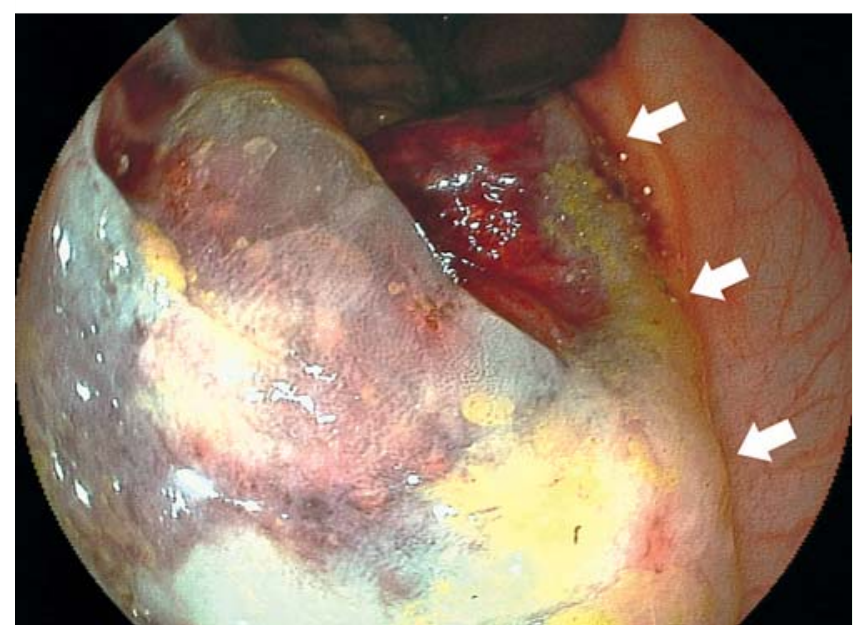

Fig. 2 Sigmoidoscopy shows necrotic mucosal lesions with hemorrhage and thick exudates in the rectum. Mucosal lesions caused by rectal burns are well demarcated from the surrounding normal rectal mucosa (arrows).

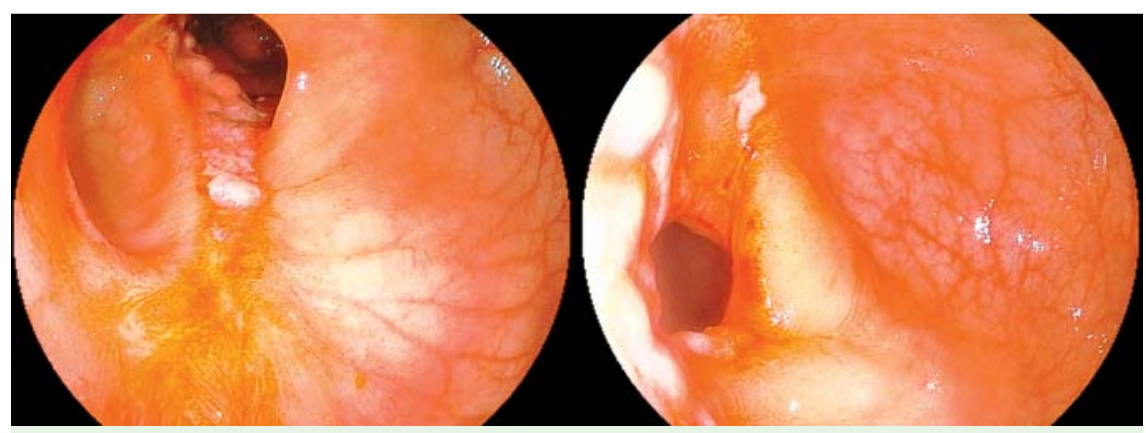

Fig. 3 Follow-up sigmoidoscopy shows benign stricture and healing-stage ulcers in the upper rectum.

\section{S. Kim, J. M. Cha, C. H. Lee, H. P. Shin, J. J. Park, K. R. Joo, J. I. Lee, J. W. Jeun, K. Lim, J. U. Lim, J. H. Choi}

Department of Internal Medicine, Kyung Hee University Hospital at Gang Dong, Kyung Hee University College of Medicine, Seoul, Republic of Korea 


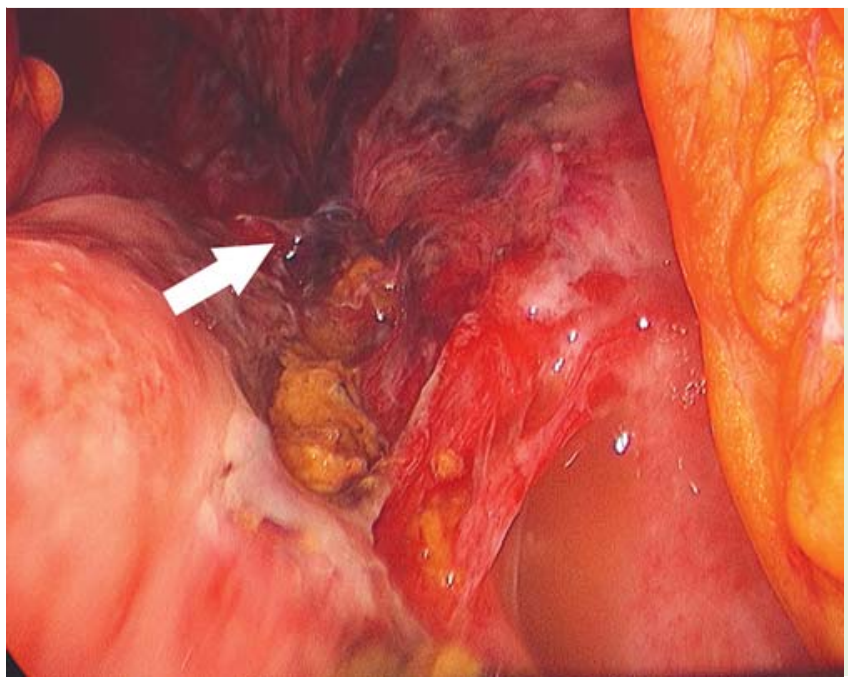

Fig. 4 Laparoscopy shows 4-cm perforation (arrow) in the upper rectum.

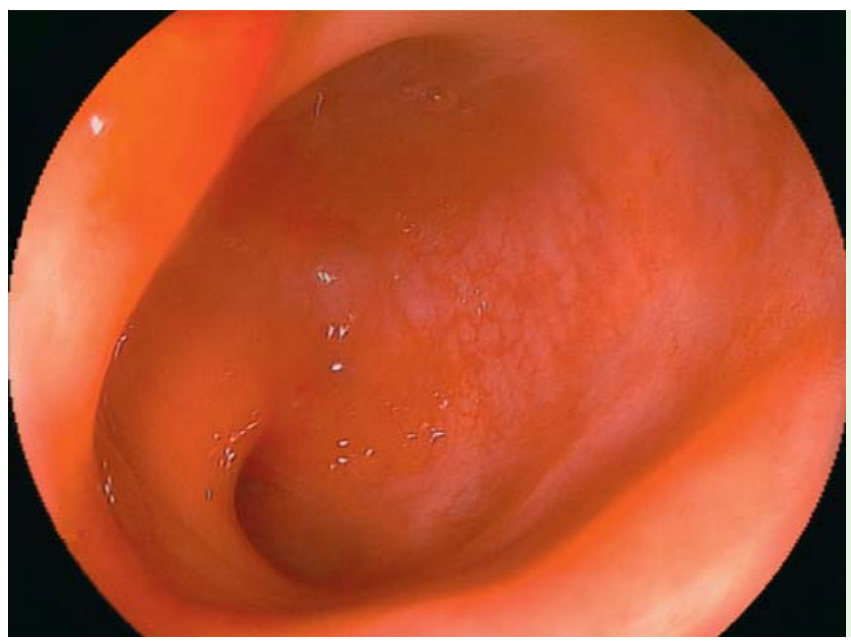

\section{References}

1 Green S. A critique of the rationale for cancer treatment with coffee enemas and diet. JAMA 1992; 268: $3224-3227$

2 Eisele JW, Reay DT. Deaths related to coffee enemas. JAMA 1980; 244: 1608-1609

3 Margolin KA, Green MR. Polymicrobial enteric septicemia from coffee enemas. West J Med 1984; 140: 460

4 Sashiyama $\mathrm{H}$, Hamahata $Y$, Matsuo $\mathrm{K}$ et al. Rectal burn caused by hot-water coffee enema. Gastrointest Endosc 2008; 68: 1008; discussion 1009

5 Jones $L E$, Norris WE. Rectal burn induced by hot coffee enema. Endoscopy 2010; 42 (Suppl 2): E26

6 Keum B, Jeen YT, Park SC et al. Proctocolitis caused by coffee enemas. Am J Gastroenterol 2010; 105: 229-230

\section{Bibliography}

DOI http://dx.doi.org/

10.1055/s-0031-1291512

Endoscopy 2012; 44: E32-E33

(C) Georg Thieme Verlag KG

Stuttgart · New York

ISSN 0013-726X

\section{Corresponding author}

\section{J. M. Cha, MD}

Department of Internal Medicine

Kyung Hee University Hospital at Gang Dong

Kyung Hee University

Gangdong-gu

Seoul 134-727

Republic of Korea

Fax: +82-2-4406295

dramc@hanmail.net 